\title{
Paratesticular Hemangioma
}

National Cancer Institute

\section{Source}

National Cancer Institute. Paratesticular Hemangioma. NCI Thesaurus. Code C162503.

A capillary or cavernous hemangioma that arises from the paratesticular region. 